\title{
Improved Vector Control of a Counter-Rotating Wind Turbine System Using Adaptive Backstepping Sliding Mode
}

\author{
Adil Yahdou*, Abdelkadir Belhadj Djilali, Zinelaabidine Boudjema, Fayçal Mehedi \\ Department of Electrical Engineering, Faculty of Technology, Hassiba Benbouali University of Chlef, Laboratoire Génie \\ Electrique et Energies Renouvelables (LGEER), Chlef 02000, Algeria
}

Corresponding Author Email: a.yahdou@univ-chlef.dz

https://doi.org/10.18280/jesa.530507

Received: 10 June 2020

Accepted: 16 August 2020

\section{Keywords:}

adaptive gains, backstepping, sliding mode, doubly fed induction generator, counter rotating wind turbine, vector control, proportional-integral regulators

\begin{abstract}
The vector control (VC) method based on proportional-integral (PI) controllers of a doubly fed induction generator (DFIG) integrated in a counter rotating wind turbine (CRWT) system have many problems, such as low dynamic performances, coupling effect between the $d-q$ axes and weak robustness against variation parametric. In order to resolve these problems, this research work proposes an adaptive backstepping sliding mode (ABSM) controller. The proposed control strategy consists in using dynamic-gains that ensures a better result than a conventional VC method. Stability of the proposed ABSM control approach has been proved by the Lyapunov method. Simulation results depicted in this research paper have confirmed the good usefulness and effectiveness of the proposed ABSM control.
\end{abstract}

\section{INTRODUCTION}

As depicted in Figure 1, the CRWT design contains of two rotors (main rotor and auxiliary rotor). According to the literature [1-3], the principal objective of this novel wind turbine (WT) is to increase the production of the electrical energy and the improvement of system yield.

DFIG is the most popular employed for variable wind speed $[4,5]$. Due to its various advantages, it is the most applied machines for WT systems. The network connected operation is possible through pulse width modulation (PWM) converters on the rotor side of the DFIG. Many strong points of the machine, which has made it the most applied, is that the semiconductor components are sized twenty to thirty percent of the global WT power. This is to ensure the stability of the electrical grid.

The standard control method of network-attached DFIG are widely based on a vector control (VC) method with stator flux orientation $[6,7]$ or stator voltage orientation $[8,9]$. In these methods of control, the PI regulators are used to regulate DFIG powers through adjusting components of rotor currents. The principal disadvantage of VC methods is that adjusting PI gains is cumbersome. Also, these PI regulators are sensitive to parameter variations of the machine.

Backstepping strategy is a recursive design and systematic methodology for nonlinear system control, which can ensure the total tracking and regulation performance $[10,11]$. The total system is subdivided into many subsystems. According to Lyapunov method, the candidate functions are chosen with variable states as pseudo control inputs. Each new pseudo control conception has been extracted on each backstepping step. When the stage terminates, the complete control input law can be extracted by the Lyapunov candidate function [12, 13]. Further, sliding mode control (SMC) has been the subject of several research works, as this control method is insensitive to disturbances and parameter variations [14].

In this research article, an ABSM controller for stator power control of DFIG driven by CRWT system, which combines the advantages of the 2-control method, SMC and backstepping, is presented to achieve a better tracking performance. The used ABSM controller can ensure closed-loop stability. An adaptive law is employed in ABSM scheme to approximate uncertainties.

This research article contains five parts as follows: in part two, the DFIG modeling is presented. In part three the VC method of the DFIG is depicted. The ABSM controller applied to the DFIG is developed in part 4. Finally, part five presents the obtained simulation results and its discussion.

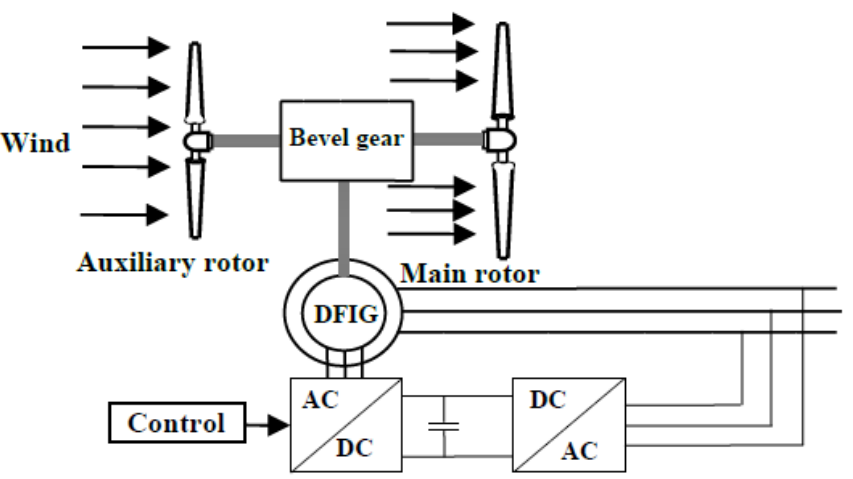

Figure 1. Configuration of a CRWT system

\section{THE DFIG MODEL}

The DFIG Park model is generally used [15-22]. The following Eq. (1) show the global generator Park model: 


$$
\left\{\begin{array}{l}
V_{d s}=R_{s} I_{d s}+\frac{d}{d t} \phi_{d s}-\omega_{s} \varphi_{q s} \\
V_{q s}=R_{s} I_{q s}+\frac{d}{d t} \phi_{q s}+\omega_{s} \varphi_{d s} \\
V_{d r}=R_{r} I_{d r}+\frac{d}{d t} \phi_{d r}-\omega_{r} \varphi_{q r} \\
V_{q r}=R_{r} I_{q r}+\frac{d}{d t} \phi_{q r}+\omega_{r} \varphi_{d r}
\end{array},\left\{\begin{array}{l}
\phi_{d s}=L_{s} I_{d s}+M I_{d r} \\
\phi_{q s}=L_{s} I_{q s}+M I_{q r} \\
\phi_{d r}=L_{r} I_{d r}+M I_{d s} \\
\phi_{q r}=L_{r} I_{q r}+M I_{q s} \\
\omega_{s}=\omega_{m}+\omega_{r}
\end{array}\right.\right.
$$

The mechanical equation is:

$$
C_{e m}=C_{r}+J \frac{d \Omega}{d t}+f \Omega
$$

where,

$$
C_{e m}=p \frac{M}{L_{s}}\left(\phi_{q s} I_{d r}-\phi_{d s} I_{q r}\right)
$$

Here, $C_{e m}$ is the electromagnetic torque.

The stator powers $\left(P_{s}\right.$ and $\left.Q_{s}\right)$ delivered from the generator is given by:

$$
\left\{\begin{array}{l}
P_{s}=V_{d s} I_{d s}+V_{q s} I_{q s} \\
Q_{s}=V_{q s} I_{d s}-V_{d s} I_{q s}
\end{array}\right.
$$

In the objective to achieve the decoupled control (vector control) of the stator powers of generator, the stator flux vector will be oriented on the $d$-axis (Figure 2). Based on Eq. (1) and neglecting $R_{s}$ we can write:

$$
\begin{gathered}
\phi_{d s}=\phi_{s} \text { and } \phi_{q s}=0 \\
\left\{\begin{array}{l}
V_{d s}=0 \\
V_{q s}=V_{s}=\omega_{s} \phi_{s}
\end{array}\right. \\
\left\{\begin{array}{l}
I_{d s}=-\frac{M}{L_{s}} I_{d r}+\frac{V_{s}}{L_{s} \omega_{s}} \\
I_{q s}=-\frac{M}{L_{s}} I_{q r}
\end{array}\right.
\end{gathered}
$$

By using Eqns. (5), (6) and (7), Eq. (4) becomes:

$$
\left\{\begin{array}{l}
P_{s}=-V_{s} \frac{M}{L_{s}} I_{q r} \\
Q_{s}=\frac{V_{s}^{2}}{\omega_{s} L_{s}}-\frac{V_{s} M}{L_{s}} I_{d r}
\end{array}\right.
$$

The electromagnetic torque of Eq. (3) becomes:

$$
C_{e m}=-p \frac{M}{L_{s}} I_{q r} \phi_{d s}
$$

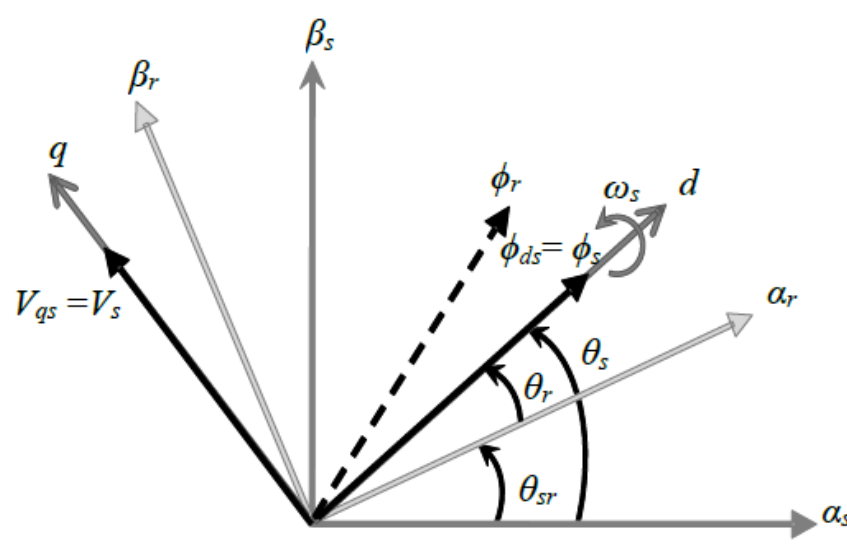

Figure 2. Stator field oriented control

Posing $\sigma=1-\frac{M^{2}}{L_{s} L_{r}}$.

Rotor voltages can be expressed by:

$$
\left\{\begin{array}{l}
V_{d r}=R_{r} I_{d r}+\sigma L_{r} \frac{d I_{d r}}{d t}-g \omega_{s} \sigma L_{r} I_{q r} \\
V_{q r}=R_{r} I_{q r}+\sigma L_{r} \frac{d I_{q r}}{d t}+g \omega_{s} \sigma L_{r} I_{d r}+g \frac{M V_{s}}{L_{s}}
\end{array}\right.
$$

\section{ABSM CONTROL DESIGN}

In the objective to control the stator reactive and active powers of the generator, ABSM control is applied. This control strategy is robust, and its parameters are adapted to eliminate the effect of the perturbation with the unknown boundaries, also, non overestimate the gains. As well as, the objective of the corrector is that its adaptation allows reducing the gain with respect to disturbances and uncertainties. Then, the gain is reduced and the regulator spends less energy. Also, another big advantage is the considerable reduced effort of system identification. As a result, the information on disturbances bounds and uncertainties is not required.

Using ABSM control strategy is very suitable because it has the desired performances, like robustness under uncertainties and decrease ripple effect.

The main goal of the ABSM regulators is to control the stator reactive and active powers of the DFIG integrated in the CRWT system to its references (Figure 3).

Step 1: the tracking error of active power is defined as:

$$
e_{1}=P_{s}^{*}-P_{s}
$$

The Lyapunov function $V\left(e_{1}\right)$ is defined as:

$$
V\left(e_{1}\right)=\frac{1}{2} \cdot e_{1}^{2}
$$

Its derivative is given by:

$$
\dot{V}\left(e_{1}\right)=e_{1} \cdot \dot{e}_{1}
$$




$$
\dot{e}_{1}=\dot{P}_{s}^{*}-\dot{P}_{s}=\dot{P}_{s}^{*}+\frac{V_{s} M}{L_{s}} \cdot \dot{I}_{q r}
$$

According to Eq. (10), the derivative of the quadrature rotor current is replaced. Eq. (14) becomes:

$$
\dot{e}_{1}=\dot{P}_{s}^{*}+\frac{V_{s} M}{\sigma \cdot L_{r} L_{s}} \cdot\left(V_{q r}-R_{r} I_{q r}-g \omega_{s} \sigma L_{r} I_{d r}-g \frac{M V_{s}}{L_{s}}\right)
$$

By replacing Eq. (15) in Eq. (13), we obtain:

$$
\begin{aligned}
\dot{V}\left(e_{1}\right) & =e_{1} \cdot \dot{e}_{1} \\
& =e_{1} \cdot\left(\dot{P}_{s}^{*}+\frac{V_{s} M}{\sigma \cdot L_{r} L_{s}} \cdot\left(V_{q r}-R_{r} I_{q r}-g \omega_{s} \sigma L_{r} I_{d r}-g \frac{M V_{s}}{L_{s}}\right)\right)
\end{aligned}
$$

The ABSM control law of active power is given by:

$$
\left\{\begin{aligned}
V_{q r}= & A\left(\dot{P}_{s}^{*}+\alpha \cdot e_{1}+k_{1} \cdot \operatorname{sign}\left(e_{1}\right)\right)+ \\
& \quad+R_{r} I_{q r}+g \omega_{s} \sigma L_{r} I_{d r}+B \\
A=- & \frac{\sigma L_{s} L_{r}}{V_{s} M} \\
B= & \frac{g M V_{s}}{L_{s}}
\end{aligned}\right.
$$

By replacing Eq. (17) in Eq. (16), we obtain:

$$
\dot{V}\left(e_{1}\right)=-\alpha \cdot e_{1}^{2}-k_{1} \cdot e_{1} \cdot \operatorname{sign}\left(e_{1}\right) \leq 0
$$

with $\alpha$ is a positive constant and $k_{l}$ is a positive dynamic gain.

Step 2: the tracking error of reactive power is defined as:

$$
e_{2}=Q_{s}^{*}-Q_{s}
$$

The Lyapunov function $V\left(e_{1}, e_{2}\right)$ is defined as:

$$
V\left(e_{1}, e_{2}\right)=\frac{1}{2} \cdot e_{1}^{2}+\frac{1}{2} \cdot e_{2}^{2}
$$

Its derivative is given by:

$$
\begin{aligned}
\dot{V}\left(e_{1}, e_{2}\right)= & e_{1} \cdot \dot{e}_{1}+e_{2} \cdot \dot{e}_{2} \\
= & -\alpha \cdot e_{1}^{2}-k_{1} \cdot e_{1} \cdot \operatorname{sign}\left(e_{1}\right)+ \\
& +e_{2} \cdot\left(\dot{Q}_{s}^{*}-\dot{Q}_{s}\right)
\end{aligned}
$$

With

$$
\dot{e}_{2}=\dot{Q}_{s}^{*}-\dot{Q}_{s}=\dot{Q}_{s}^{*}+\frac{V_{s} M}{L_{s}} \cdot \dot{I}_{d r}
$$

According to Eq. (10), the derivative of the direct rotor current is replaced. Eq. (22) becomes:

$$
\dot{e}_{2}=\dot{Q}_{s}^{*}+\frac{V_{s} M}{\sigma \cdot L_{r} L_{s}} \cdot\left(V_{d r}-R_{r} I_{d r}+g \omega_{s} \sigma L_{r} I_{q r}\right)
$$

By replacing Eq. (23) in Eq. (21), we obtain:

$$
\begin{aligned}
\dot{V}\left(e_{1}, e_{2}\right)= & e_{1} \cdot \dot{e}_{1}+e_{2} \cdot \dot{e}_{2} \\
= & -\alpha \cdot e_{1}^{2}-k_{1} \cdot e_{1} \cdot \operatorname{sign}\left(e_{1}\right) \\
& +e_{2} \cdot\left(\dot{Q}_{s}^{*}+\frac{V_{s} M}{\sigma \cdot L_{r} L_{s}} \cdot\left(V_{d r}-R_{r} I_{d r}+g \omega_{s} \sigma L_{r} I_{q r}\right)\right)
\end{aligned}
$$

The ABSM control law of reactive power is given by:

$$
V_{d r}=A\left(\dot{Q}_{s}^{*}+\beta . e_{2}+k_{2} . \operatorname{sign}\left(e_{2}\right)\right)+R_{r} I_{d r}-g \omega_{s} \sigma L_{r} I_{q r}
$$

By replacing Eq. (25) in Eq. (24), we obtain:

$$
\dot{V}\left(e_{1}, e_{2}\right)=-\alpha \cdot e_{1}^{2}-k_{1} \cdot e_{1} \cdot \operatorname{sign}\left(e_{1}\right)-\beta \cdot e_{2}^{2}-k_{2} \cdot e_{2} \cdot \operatorname{sign}\left(e_{2}\right) \leq 0
$$

with $\beta$ is a positive constant and $\mathrm{k}_{2}$ is a positive dynamic gain. where, the adaptive gains of ABSM control, $\mathrm{k}_{1}$ and $\mathrm{k}_{2}$ are dynamics, given us:

$$
\left\{\begin{array}{l}
k_{i}=a_{i} \cdot\left|\eta_{i}\right|+b_{i} \\
i=1,2
\end{array}\right.
$$

where, $a_{i}>0, b_{i}>0, \eta_{i}$ is the average value of the $\operatorname{sign}\left(e_{i}\right)$ function $(i=1,2)$.

The dynamical ABSM control increases the gains in order to stabilize the system. Then, if the sliding mode is achieved, the control gains begin to decrease.

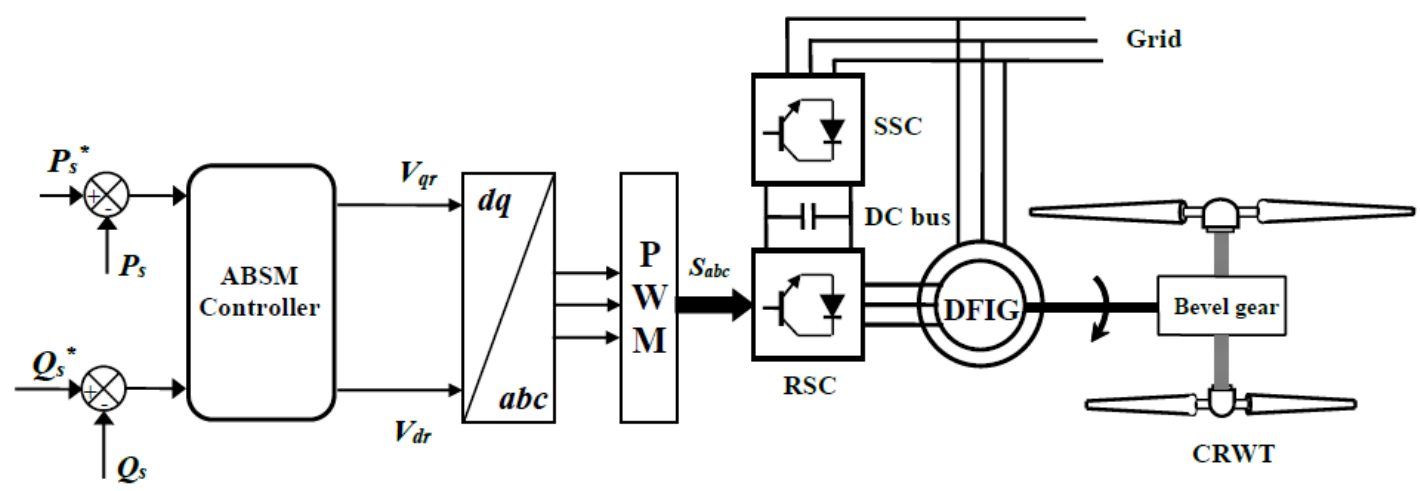

Figure 3. Stator power control with ABSM controller of a CRWT system 


\section{SIMULATION RESULTS}

The proposed control (ABSM) depicted in section 3 was validated, using the MATLAB/Simulink software.

The DFIG used in our work has the following parameters: nominal power: $P_{n}=1.5 \mathrm{MW}$, stator voltage: $V_{\mathrm{s}}=398 \mathrm{~V}$, rotor resistance: $R_{r}=0.021 \Omega$, stator resistance: $R_{s}=0.012 \Omega$, rotor self-inductance: $L_{\mathrm{r}}=0.0136 \quad \mathrm{H}, \quad$ stator self-inductance $L_{\mathrm{s}}=0.0137 \mathrm{H}$, mutual inductance: $M=0.0135 \mathrm{H}$, stator frequency: $f_{s}=50 \mathrm{~Hz}$, nominal rotor speed: $\Omega=150 \mathrm{rad} / \mathrm{s}$, number of pole pairs: $p=2$ [17].

\subsection{Reference tracking test (RTT)}

In this first test the DFIG rotor speed is equal at its nominal value $(\Omega=150 \mathrm{rad} / \mathrm{s})$. Figures 4-6 present obtained simulation results for the RTT. As illustrated in Figure 4, for the two powers control methods (PI and ABSM), the reactive and active powers of DFIG almost perfectly track their references. Nevertheless, the VC based on PI controller where the effect of coupling between the 2 axes is clear, we notice that the ABSM controller ensures the decoupling between them.

Figure 5 illustrate the error curves for both stator power control methods (PI and ABSM) for RTT. It can be noticed that the important peak value occurred for PI controller (around to 20\%). However, a significant reduction of this value can be observed when the proposed ABSM controller is applied. Also, an important peak can be noticed in time of changing stator power reference tracking for PI controller. Nevertheless, this peak value is minimized for the ABSM controller.

The dynamic gain curves $k_{1}$ and $k_{2}$ of the ABSM control is depicted in Figure 6 for the RTT, we notice that this gains are online adapted for obtained the good reference tracking.
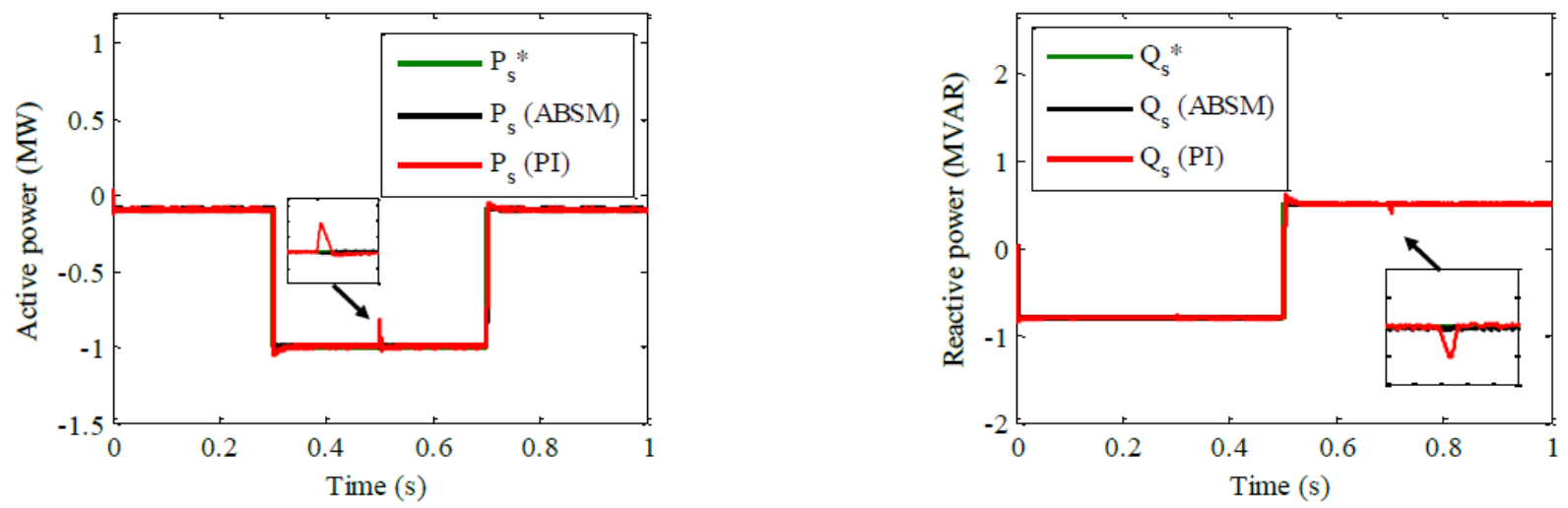

Figure 4. Active and reactive power curves (RTT)
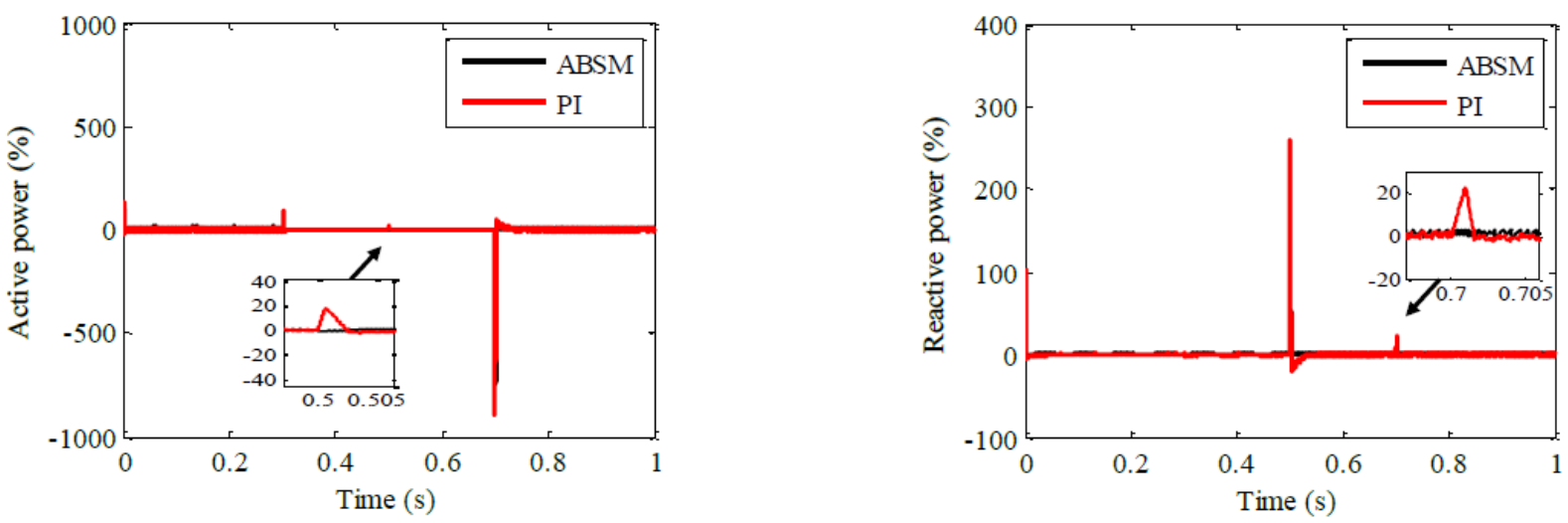

Figure 5. Error curves (RTT)

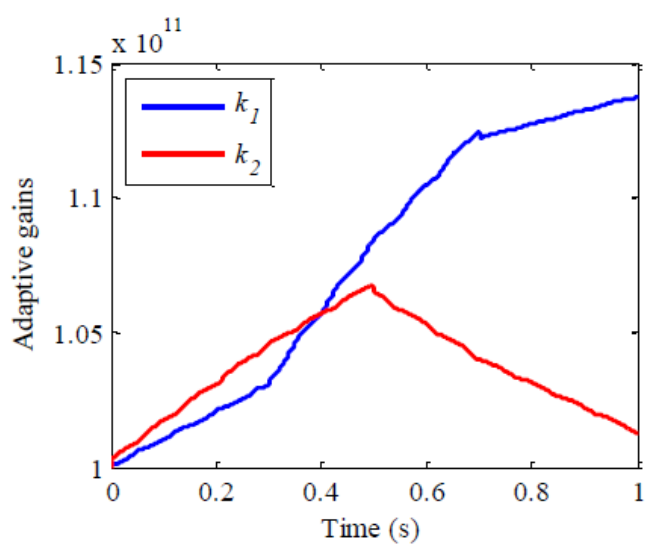

Figure 6. Adaptive gain curves (RTT)

\subsection{Robustness test (RT)}

In this second test, it is supposed that the rotor resistance $\left(R_{r}\right)$ value is increased up to $100 \%$. Also, the values of inductances $L_{s}, L_{r}, M$ are decreased up to $50 \%$. The DFIG is turning with constant speed $(\Omega=150 \mathrm{rad} / \mathrm{s})$. Obtained results for the RT are depicted in Figures 7-9. As shown in these figures, we noticed that on the reactive and active power curves, the generator parameter variations present a clear effect. This effect is more important for VC based on PI controller than for ABSM. Therefore, it can be concluded that the proposed stator power control with ABSM technique is more robust than the stator power control with PI regulator one.

Figure 10 presents the time evolution of the adaptive gains 
( $k_{1}$ and $k_{2}$ ) of ABSM technique for RT, we notice that this gains are online adapted for obtained the good robustness.

Figures 11-12 illustrate the total harmonic distortion (THD) of the stator current of the DFIG for both stator power control methods (PI and ABSM) for RT. It can be noticed that the THD value is reduced for stator power ABSM controller (THD $=1.15 \%)$ compared to PI controller $($ THD $=2.20 \%)$.
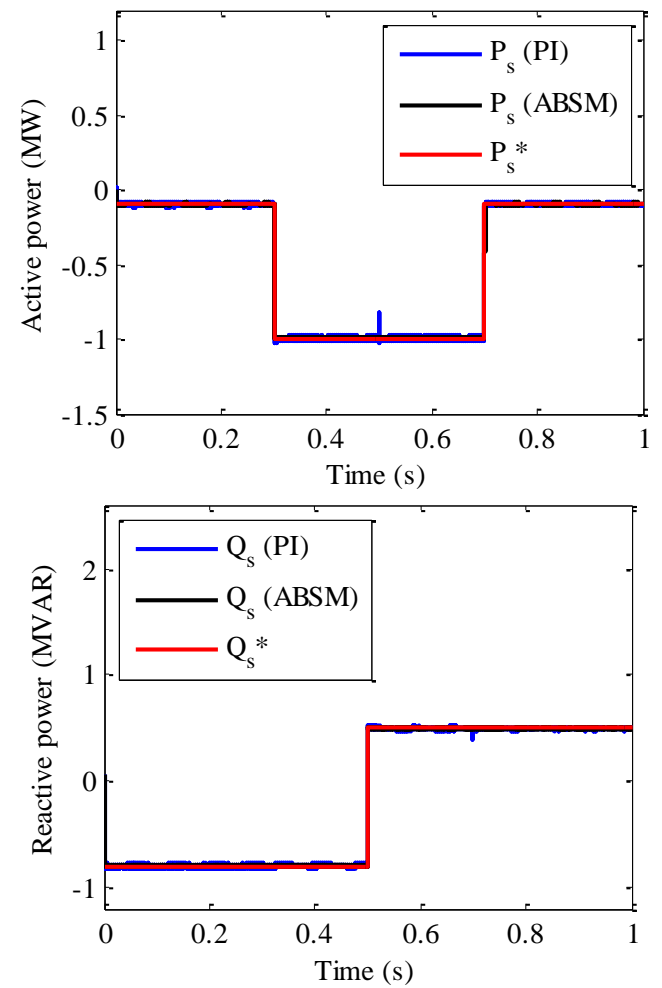

Figure 7. Active and reactive power curves (RT)

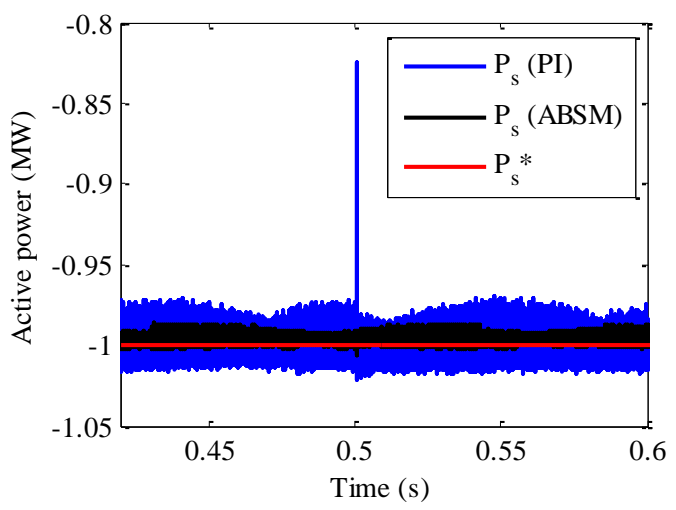

Figure 8. Zoom in the active power (RT)

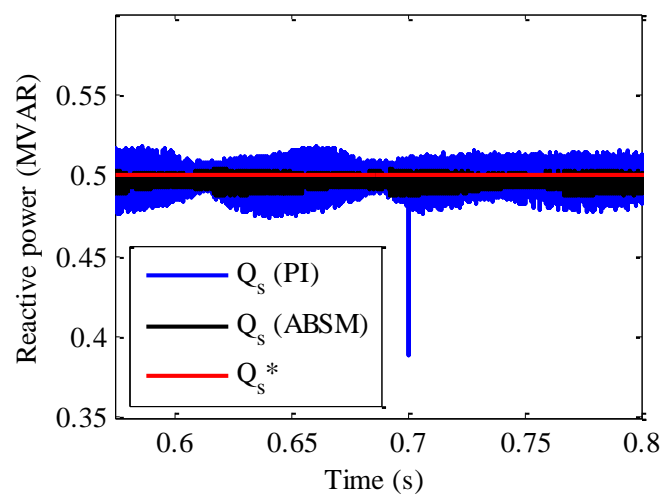

Figure 9. Zoom in the reactive power (RT)

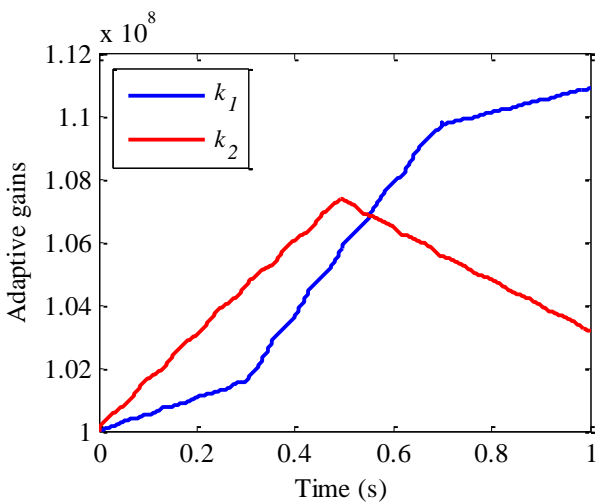

Figure 10. Adaptive gain curves (RT)

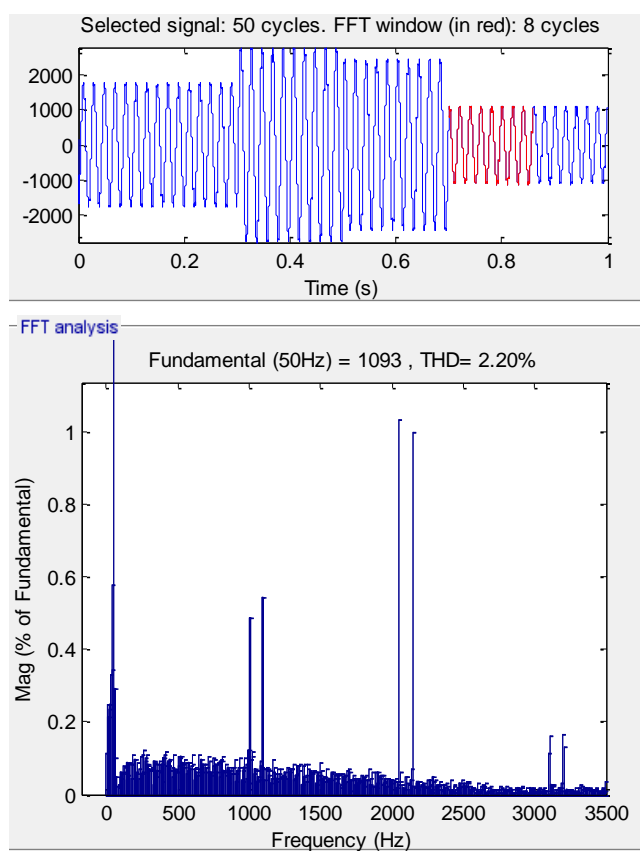

Figure 11. THD of one phase stator current for PI controller (RT)
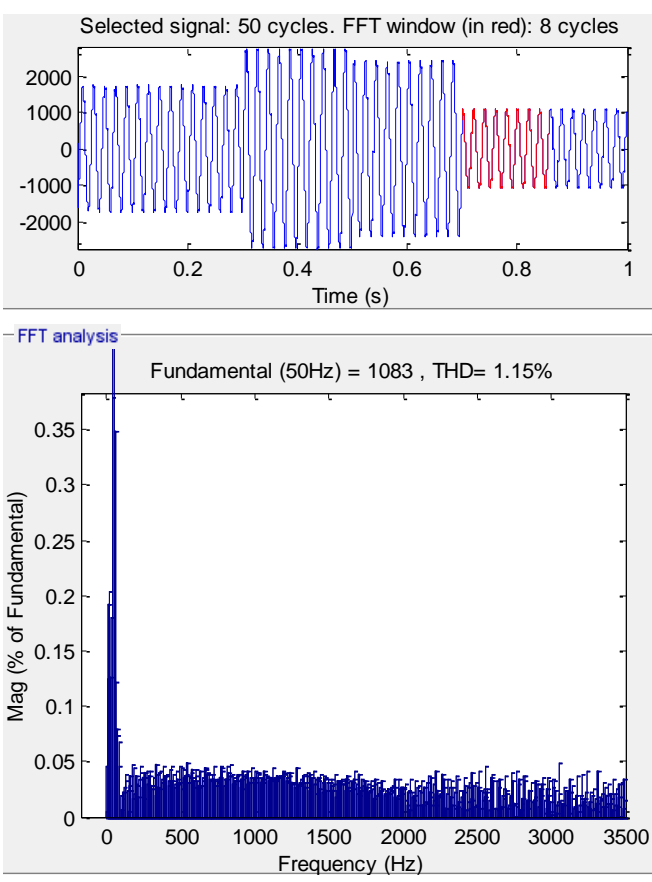

Figure 12. THD of one phase stator current for ABSM controller (RT) 


\section{CONCLUSION}

In this work, the ABSM control of a CRWT based DFIG connected to the grid by the stator and fed by the PWM converters by the rotor side has been proposed. Obtained results show a good quality performance of the proposed control (ABSM) compared to VC based on PI controller in terms of reduced coupling effect and shows an excellent robustness for variation parametric. Also, the simulation results illustrate a reduction of the THD value and the stator reactive and active power ripple for the ABSM controller compared to PI controller. Finally, it can be concluded that a control technique such as ABSM control can be a very effective solution for stator power control of DFIG driven by CRWT.

\section{REFERENCES}

[1] Vasel-Be-Hagh, A., Archer, C.L. (2017). Wind farms with counter-rotating wind turbines. Sustainable Energy Technologies and Assessments, 24: 19-30. https://doi.org/10.1016/j.seta.2016.10.004

[2] Cho, W., Lee, K., Choy, I., Back, J. (2017). Development and experimental verification of counter-rotating dual rotor/dual generator wind turbine: Generating, yawing and furling. Renewable Energy, 114: 644-654. https://doi.org/10.1016/j.renene.2017.06.083

[3] Lee, S., Son, E., Lee, S. (2013). Velocity interference in the rear rotor of a counter-rotating wind turbine. Renewable Energy, 54: 235-240. https://doi.org/10.1016/j.renene.2012.08.003

[4] Wang, X., Sun, D., Zhu, Z.Q. (2017). Resonant-based backstepping direct power control strategy for DFIG under both balanced and unbalanced grid conditions. IEEE Transactions on Industry Applications, 53(5): 4821-4830. https://doi.org/10.1109/TIA.2017.2700280

[5] Prajapat, G.P., Senroy, N., Kar, I.N. (2017). Wind turbine structural modeling consideration for dynamic studies of DFIG based system. IEEE Transactions on Sustainable Energy, 8(4): 1463-1472. https://doi.org/10.1109/TSTE.2017.2690682

[6] Pena, R., Clare, J.C., Asher, G.M. (1996). Doubly fed induction generator using back-to-back PWM converters and its application to variable-speed wind energy generation. IEE Proceedings - Electric Power Applications, 143(3): 231-241. https://doi.org/10.1049/ip-epa:19960288

[7] Xu, L., Cheng, W. (1995). Torque and reactive power control of a doubly fed induction machine by position sensorless scheme. IEEE Transactions on Industry Applications, $\quad 31(3)$ : 636-642. https://doi.org/10.1109/28.382126

[8] Muller, S., Deicke, M., De Doncker, R.W. (2002). Doubly fed induction generator systems for wind turbines. IEEE Industry Applications Magazine, 8(3): 26-33. https://doi.org/10.1109/2943.999610

[9] Hu, J., He, Y. (2006). Dynamic modelling and robust current control of wind-turbine driven DFIG during external AC voltage dip. Journal of Zhejiang University$\begin{array}{llll}\text { Science } & \text { A, } & \text { 1757-1764. }\end{array}$ https://doi.org/10.1631/jzus.2006.A1757

[10] Bin, D., Jiang, W, Fei, X.Y. (2006). Synchronizing two coupled chaotic neurons in external electrical stimulation using backstepping control. Chaos, Solitons \& Fractals, 29(1): https://doi.org/10.1016/j.chaos.2005.08.027

[11] Liu, J.Z., Deng, H., Hu, C., Hua, Z., Chen, W. (2017). Adaptive backstepping sliding mode control for 3-DOF permanent magnet spherical actuator. Aerospace Science and Technology, 67: 62-71. http://doi.org/10.1016/j.ast.2017.03.032

[12] Xu, D., Wang, G., Yan, W., Yan, X. (2019). A novel adaptive command-filtered backstepping sliding mode control for PV grid-connected system with energy storage. Solar Energy, 178: 222-230. https://doi.org/10.1016/j.solener.2018.12.033

[13] Kim, Y., Oh, T.H., Park, T., Lee, J.M. (2019). Backstepping control integrated with Lyapunov-based model predictive control. Journal of Process Control, 73: 137-146. https://doi.org/10.1016/j.jprocont.2018.12.007

[14] Utkin, V.I. (1993). Sliding mode control design principles and applications to electric drives. IEEE Transactions on Industrial Electronics, 40(1): 23-36. https://doi.org/10.1109/41.184818

[15] Kahla, S., Soufi, Y., Sedraoui, M., Bechouat, M. (2015). On-off control based particle swarm optimization for maximum power point tracking of wind turbine equipped by DFIG connected to the grid with energy storage. International Journal of Hydrogen Energy, 40(39): 13749-13758. https://doi.org/10.1016/j.ijhydene.2015.05.007

[16] Yaichi, I., Semmah, A., Wira, P. (2019). Direct power control of a wind turbine based on doubly fed induction generator. European Journal of Electrical Engineering, 21(5): 457-464. https://doi.org/10.18280/ejee.210508

[17] Boudjema, Z., Taleb, R., Djeriri, Y., Yahdou, A. (2017). A novel direct torque control using second order continuous sliding mode of a doubly fed induction generator for a wind energy conversion system. Turkish Journal of Electrical Engineering \& Computer Sciences, 25(2): 965-975. https://doi.org/10.3906/elk-1510-89

[18] Benbouhenni, H., Boudjema, Z., Belaidi, A. (2020). DPC based on ANFIS super-twisting sliding mode algorithm of a doubly-fed induction generator for wind energy system. Journal Européen des Systèmes Automatisés, 53(1): 69-80. https://doi.org/10.18280/jesa.530109

[19] Abdeddaim, S., Betka, A. (2013). Optimal tracking and robust power control of the DFIG wind turbine. International Journal of Electrical Power \& Energy Systems, 49: 234-242. https://doi.org/10.1016/j.ijepes.2012.12.014

[20] Yahdou, A., Boudjema, Z., Taleb, R., Belhadj Djilali, A. (2018). Backstepping sliding mode control of a dual rotor wind turbine system. 2018 IEEE, CISTEM, Algeria. https://doi.org/10.1109/CISTEM.2018.8613409

[21] Yahdou, A., Hemici, B., Boudjema, Z. (2015). Sliding mode control of dual rotor wind turbine system. The Mediterranean Journal of Measurement and Control, 11(2): 412-419.

[22] Boudjema, Z., Taleb, R., Yahdou, A. (2016). A new DTC scheme using second order sliding mode and fuzzy logic of a DFIG for wind turbine system. International Journal of Advanced Computer Science and Applications, 7(8): 49-56. https://doi.org/10.14569/IJACSA.2016.070808 
NOMENCLATURE

ABSM Adaptive Backstepping Sliding Mode

DFIG Doubly-Fed Induction Generator

CRWT Counter Rotating Wind Turbine

PI Proportional-Integral

PWM Pulse Width Modulation

RSC Rotor Side Converter

RTT Reference Tracking Test

RT Robustness Test

SMC Sliding Mode Control

SSC Stator Side Converter

THD Total Harmonic Distortion

VC Vector Control

WT Wind Turbine

$d, q \quad$ Synchronous d-q axis

$R_{r}, R_{s} \quad$ Rotor and stator resistances

$L_{r}, L_{s} \quad$ Rotor and stator self-inductances

$M \quad$ Mutual inductance

$V_{d s}, V_{q s} \quad$ Direct and quadrature stator voltages
$V_{d r}, V_{q r}$

$I_{d s}, I_{q s}$

$I_{d r}, I_{q r}$

$\phi_{d s}, \phi_{q s}$

$\phi_{d r}, \phi_{q r}$

$P_{s}, Q_{s}$

$P_{s}{ }^{*}$

$Q_{s}{ }^{*}$

$C_{e m}$

$\Omega$

$C_{r}$

$f$

$J$

$p$

$k_{1}, k_{2}$

$\omega_{s}$

$\omega_{r}$

$\omega_{m}$

$\alpha, \beta$
Direct and quadrature rotor voltages

Direct and quadrature stator currents

Direct and quadrature rotor currents

Direct and quadrature stator flux

Direct and quadrature rotor flux

Active and reactive powers

Reference active power

Reference reactive power

Electromagnetic Torque

Mechanical rotor speed

Load Torque

Viscous friction coefficient

The inertia

Number of pole pairs

Positive adaptive gains

Stator electrical pulsation

Rotor electrical pulsation

Mechanical pulsation

Positive constant gains 